\title{
Evaluation of serum perlecan levels in pregnancy with mild and severe preeclampsia
}

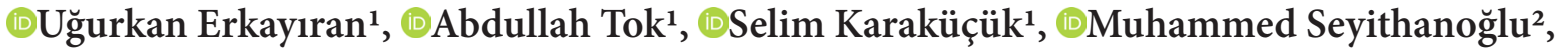 \\ (1)Tufan Arslanca ${ }^{3}$ \\ ${ }^{1}$ Kahramanmaraş Sütçü İmam University, Faculty of Medicine, Department of Obstetrics and Gynecology, Kahramanmaraş, Turkey \\ ${ }^{2}$ Kahramanmaraş Sütçü İmam University, Faculty of Medicine, Department of Biochemistry, Kahramanmaraş, Turkey \\ ${ }^{3}$ Ankara Ufuk University Faculty of Medicine, Department of Obstetrics and Gynecology, Ankara, Tukey
}

Cite this article as: Erkayıran U, Tok A, Karaküçük S, Seyithanoğlu M, Arslanca T. Evaluation of serum perlecan levels in pregnancy with mild and severe preeclampsia. J Health Sci Med 2021; 4(5): 538-542.

\begin{abstract}
Aim: To determine the levels of perlecan contributing to angiogenesis and autophagy inhibition in severe and mild preeclamptic women.

Material and Method: The study included a total of 89 patients as 3 group including severe preeclampsia as group 1 (n:30), mild preeclampsia as group 2 (n:30), and control as group 3 (n:29). All the groups were evaluated in terms of prepartum maternal serum perlecan levels.

Results: The Perlecan level of the group 1 was at higher levels than others $(\mathrm{p}<0.0001)$. The Perlecan level in the group 2 was higher than the control ( $\mathrm{p}<0.0001)$. In the correlation analysis, AST $(\mathrm{p}<0.0001)$, ALT $(\mathrm{p}<0.0001)$, systolic blood pressure $(\mathrm{p}<0.0001)$, diastolic blood pressure $(\mathrm{p}<0.0001)$, creatinine $(\mathrm{p}<0.0001)$, proteinuria $(\mathrm{p}<0.0001)$, and LDH $(\mathrm{p}<0.0001)$ were positively correlated with perlecan level in the severe preeclampsia.

Conclusion: Serum perlecan levels were higher in preeclamptic pregnant women and this increased more especially in those with severe preeclampsia clinic.
\end{abstract}

Keywords: Perlecan, preeclampsia, autophagy, angiogenesis, pathophysiology

\section{INTRODUCTION}

Preeclampsia, characterized by hypertension and proteinuria, is one of the most important clinical conditions during pregnancy (1). It is seen in 3-5\% of all pregnancies worldwide and seriously affects the life of the mother and baby (2).

Various factors have been suggested in studies investigating the conditions that prevent the development of the placental bed (3). There are crucial factors in the pathogenesis of preeclampsia such as systemic inflammation, hormonal and biochemical changes in the placenta, increase and decrease of proteins in maternal blood (4). Uteroplacental circulatory failure that develops as a result of placental dysfunction in the first trimester plays a critical role in its pathogenesis (5). Placental dysfunction reduces the invasion of trophoblasts into the decidua, and this decrease causes maternal hyperdynamic circulation and endothelial activation by causing villus hyperplasia, placental hypoperfusion, and vasopressor release by causing modification in spiral arteries $(6,7)$.
Hypoxia occurring at the physiological level causes trophoblast invasion in the early period of placenta formation by affecting autophagy at the basal level (8). Autophagy reduces the aggregation of proteins in cells, that is, it has a protective effect on the cell; by inhibiting autophagy, proteins such as the amyloid increase in the cell and impair cell function (9). The findings explaining the relationship between preeclampsia and autophagy are still controversial.

In that term, Perlecan, a derivative of heparan sulfate, one of the main components of the basement membrane, comes to the fore because it increased angiogenesis and reduced autophagy according to the recent studies (1012). Furthermore, perlecan level increases from the $17^{\text {th }}$ week to the $40^{\text {th }}$ week of pregnancy, but although its physiological role in pregnancy is not known exactly (13).

The present study aimed to analyze preaclampsia in separate groups and measured the prepartum perlecan levels in maternal serum to investigate its effect in preeclampsia. 


\section{MATERIAL AND METHOD}

\section{Study Design}

The study was designed as a level-II prospective observational clinical research and performed after the approval by Clinical Research Ethics Committee of Kahramanmaraş Sütçü İmam University, Faculty of Medicine (Date: 29/08/2018, Decision No: 06, Session: 2018/5). All procedures were carried out in accordance with the ethical rules and the principles of the Declaration of Helsinki. The written informed consents were obtained from the patients.

The study included a total of 89 patients who admitted to the Gynecology and Obstetrics Department on 2019 to 2020 as 3 group including severe preeclampsia as group 1 (n:30), mild preeclampsia as group 2 (n:30), and control as group 3 (n:29). All the groups were evaluated in terms of prepartum maternal serum perlecan levels.

\section{Inclusion/Exclusion Criteria}

Patients with 20 to 36 pregnancy weeks were included in the study. Patients with blood pressure above 140/90 $\mathrm{mmHg}$ and with proteinuria more than $300 \mathrm{mg} / \mathrm{l}$ in 24-hour urine were included in the mild preeclampsia group. In addition, those with blood pressure above $160 / 110 \mathrm{mmHg}$, those with more than twice as high AST and ALT values, those with creatinine value above 1.1 $\mathrm{mg} / \mathrm{dl}$, those with thrombocyte count less than 100,000 $\mu \mathrm{l}$, those with pulmonary edema, those with epigastric pain and with no other diagnosis, those with a new-onset headache non-responsive to drugs, and those with visual symptoms were included in the severe preeclampsia group. Patients whose gestational week were compatible with the patients in the other group and who did not have chronic hypertension, gestational hypertension, gestational diabetes mellitus, renal disease, autoimmune disease, and multiple pregnancies were included in the control group.

\section{Definitions of Preeclampsia}

Mild preeclampsia: New onset blood pressure is 140 to $159 \mathrm{mmHg}$ systolic and/or 90 to $109 \mathrm{mmHg}$ diastolic. Proteinuria is $300 \mathrm{mg} / 24$ hours; or $\geq 1+$ on 2 random urine samples, collected at least 4 hours apart or protein: creatinine ratio is $\geq 0.3 \mathrm{mg} / \mathrm{dL}$. In the absence of proteinuria, the following factors should be present: thrombocytopenia with platelets count $<100,000 / \mathrm{uL}$; serum creatinine $\geq 1.1 \mathrm{mg} / \mathrm{L}$ or a doubling of the serum creatinine concentration in the absence of another renal disease; impaired liver function with elevated blood concentrations of liver transaminases to twice normal concentration. In addition to them; Pulmonary oedema, Cerebral or visual disturbances,
Severe preeclampsia: BP is $\geq 160 \mathrm{mmHg}$ systolic and/ or $\geq 110 \mathrm{mmHg}$ diastolic on two occasions and taken at least six hours apart or Proteinuria is $300 \mathrm{mg} / 24$ hours; or $\geq 1+$ on 2 random urine samples, collected at least 4 hours apart or protein: creatinine ratio is $\geq 0.3 \mathrm{mg} / \mathrm{dL}$. In the absence of proteinuria, the following factors should be present: thrombocytopenia with platelets count $<100000 / \mathrm{ul}$, serum creatinine $\geq 1.1 \mathrm{mg} / 1$ or a doubling of the serum creatinine levels in the absence of another renal disease, the impaired liver function as indicated by elevated blood levels of liver transaminases to twice the normal concentration, pulmonary oedema, cerebral or visual disturbances.

\section{Clinical Measurements}

The gestational ages of the patients at the time of diagnosis were confirmed by the first-trimester crown-rump length and the last menstrual period. Gravida and the parity of all patients included in the study were questioned. Body mass indexes were calculated through height and weight measurements $\left(\mathrm{kg} / \mathrm{m}^{2}\right)$. Their systolic and diastolic blood pressure values were recorded.

\section{Laboratory Analysis}

Proteinuria values were determined in 24-hour urine. Hemogram, AST, ALT, creatinine, uric acid, and LDH were tested. In addition, venous blood samples were taken from the antecubital area by phlebotomy method to simultaneously see the perlecan level of patients. The blood sample tubes were kept in an upright position for 10-20 minutes for coagulation and then centrifuged at $+4^{\circ} \mathrm{C}$ and $4000 \mathrm{rpm}$ for 10 minutes. Serum samples obtained were aliquoted and placed in the deep freezer at $-80^{\circ} \mathrm{C}$ and kept until the day of analysis. On the day, when all serum samples were at room temperature, measurements were made using the enzyme-linked immunosorbent assay (ELISA) kit, following the manufacturer's instructions. (BOSTER antibody and ELISA experts, Human Endorepellin/HSP2 ELISA Kit PicoKineTM Catalog number: EK1760, Boster Biological Technology, USA). Detection range of the kit was $0.624-40 \mathrm{ng} / \mathrm{mL}$ and detection sensitivity was $<0.05$ $\mathrm{ng} / \mathrm{mL}$.

\section{Statistical Assessments}

The collected patient data were analyzed using the Statistical Package For Social Sciences - SPSS for Windows 23.0 package (IBM Statistical Package, New York, USA). Mean and standard deviation were given as descriptive values for continuous data and variables with normal distribution, and the median for non-normally distributed variables. For comparisons between groups, the "ANOVA Test" was used for more than two groups in normally distributed variables, and the "Kruskal Wallis 
H-Test" was used for more than two groups in nonnormally distributed variables. Post-Hoc Tukey test was used to determine which parameters the significance arose from in the evaluations that were found to be significant. the possible relation between labaratory parameters and serum perlecan level was investigated with spearman correlation test. Results were considered statistically significant in cases where the $\mathrm{p}$-value was less than 0.05 .

\section{RESULTS}

There was no significant difference between the three groups in terms of age, body mass index (BMI), gravida, and parity between the groups. All three groups were evaluated in terms of perlecan levels. Group 1's perlecan level was found higher than the other groups and this difference was statistically significant when compared with the other two groups. Compared with the control group, a significant increase was found in favor of Group 2. There was also a significant difference between the groups in terms of SBP and DBP. There was no significant difference between the groups in terms of hemoglobin and platelet values $(\mathrm{p}=0.555, \mathrm{p}=0.056$, respectively). While there was no significant difference in AST and ALT values between group 2 and group 3, a significantly higher difference was found between group 1 and the other groups. While there was no significant difference between group 1 and group 2 in terms of creatinine values, a significant difference was observed between these groups and the control group. While there was no difference between group 1 and group 2 in terms of $\mathrm{LDH}$ and uric acid values, a significant difference was detected between these groups and the control group. In terms of proteinuria, significant differences were found between group 1 and group 2, between group 1 and the control group, and between group 2 and the control group (Table 1). In terms of correlation of perlecan levels in groups with hematological parameters, it was observed that perlecan level was positively correlated with SBP, DBP, AST, ALT, creatinine, proteinuria, and LDH levels in Group 1. It was observed that perlecan levels of Group 2 were positively correlated with AST, ALT, creatinine, proteinuria, LDH, and uric acid levels and negatively correlated with platelet levels (Table 2). The distribution and mean value of perlecan levels among the groups were found to be $2.43 \mathrm{ng} / \mathrm{mL}$ in the severe preeclampsia group, $1.22 \mathrm{ng} / \mathrm{mL}$ in the mild preeclampsia group, and $0.89 \mathrm{ng} / \mathrm{mL}$ in the control group. The distribution range of perlecan level was very wide in the severe preeclampsia group, while it was narrow in the control group (Figure).

Table 2. Analysis results of the correlation of perlecan levels of groups with other hematological parameters

\begin{tabular}{|c|c|c|c|c|c|c|}
\hline \multirow{2}{*}{ Characteristics } & \multicolumn{2}{|c|}{$\begin{array}{c}\text { Severe } \\
\text { preeclampsia }\end{array}$} & \multicolumn{2}{|c|}{$\begin{array}{c}\text { Mild } \\
\text { preeclampsia }\end{array}$} & \multicolumn{2}{|c|}{ Control } \\
\hline & $\mathbf{R}$ & $\underset{\text { values }}{\mathbf{p}}$ & $\mathbf{R}$ & $\begin{array}{c}\mathbf{p} \\
\text { value }\end{array}$ & $\mathbf{R}$ & $\begin{array}{c}\mathrm{p} \\
\text { value }\end{array}$ \\
\hline SBP & 0.506 & 0.004 & 0.322 & 0.082 & 0.087 & 0.653 \\
\hline DBP & 0.594 & 0.001 & 0.321 & 0.083 & 0.107 & 0.580 \\
\hline $\mathrm{Hb}$ & 0.104 & 0.585 & 0.169 & 0.373 & 0.352 & 0.061 \\
\hline Platelet & -0.286 & 0.125 & -0.414 & 0.023 & 0.345 & 0.067 \\
\hline AST & 0.755 & $<0.0001$ & 0.429 & 0.018 & 0.326 & 0.084 \\
\hline ALT & 0.697 & $<0.0001$ & 0.423 & 0.020 & 0.285 & 0.134 \\
\hline Creatinine & 0.554 & 0.001 & 0.412 & 0.024 & 0.171 & 0.376 \\
\hline Proteinuria & 0.457 & 0.011 & 0.478 & 0.008 & -0.242 & 0.205 \\
\hline $\mathrm{LDH}$ & 0.619 & $<0.0001$ & 0.385 & 0.035 & 0.176 & 0.361 \\
\hline Uric Acid & 0.312 & 0.093 & 0.386 & 0.035 & 0.233 & 0.224 \\
\hline
\end{tabular}

\begin{tabular}{|c|c|c|c|c|c|}
\hline Characteristics & Total (n:89) & $\begin{array}{l}\text { Severe Preeclampsia } \\
\text { (Group 1) }(n=30)\end{array}$ & $\begin{array}{l}\text { Mild Preeclampsia } \\
\text { (Group 2) }(n=30)\end{array}$ & Control $(n=29)$ & p-value \\
\hline Age (year) & $27(15)$ & $27(15)$ & $27(13)$ & $25(14)$ & 0.547 \\
\hline BMI $\left(\mathrm{kg} / \mathrm{m}^{2}\right)$ & $23.9(20.2)$ & $26.2(20.2)$ & $23.9(16.2)$ & $23.7(18)$ & 0.655 \\
\hline Gestational age (weeks) & $32(13)$ & $33(11)$ & $31(12)$ & $32(10)$ & 0.188 \\
\hline Gravidity & $2(5)$ & $2(4)$ & $2(5)$ & $2(5)$ & 0.995 \\
\hline Parity & $1(4)$ & $0.5(4)$ & $1(4)$ & $1(4)$ & 0.997 \\
\hline Perlecan level (ng/ml) & $1.22(5.97)$ & $2.43(5.56)$ & $1.22(3.07)$ & $0.89(1.24)$ & $<0.0001^{k}$ \\
\hline SBP (mmHg) & $145(176)$ & $164.5(136)$ & $148.5(18)$ & $113(45)$ & $<0.0001^{k}$ \\
\hline $\mathrm{DBP}(\mathrm{mmHg})$ & $92.28 \pm 18.4$ & $107.5 \pm 17.4$ & $95.36 \pm 7.1$ & $73.27 \pm 7.95$ & $<0.0001^{\circ}$ \\
\hline $\mathrm{Hb}(\mathrm{gr} / \mathrm{dl})$ & $10.75 \pm 1.34$ & $10.91 \pm 1.48$ & $10.54 \pm 1.4$ & $10.8 \pm 1.1$ & 0.555 \\
\hline Platelet $\left(10^{3} / \mu \mathrm{L}\right)$ & $214.3 \pm 67.5$ & $194.5 \pm 69.7$ & $212.7 \pm 68.7$ & $236.4 \pm 58.9$ & 0.056 \\
\hline $\operatorname{AST}(\mathrm{U} / \mathrm{L})$ & $19(256)$ & $29(254)$ & $19(27)$ & $18(19)$ & $<0.0001^{k}$ \\
\hline $\operatorname{ALT}(\mathrm{U} / \mathrm{L})$ & $12(258)$ & $25.5(257)$ & $8.5(27)$ & $11(25)$ & $<0.0001^{k}$ \\
\hline Creatinine (mg/dL) & $0.53(1.06)$ & $0.65(0.99)$ & $0.54(0.62)$ & $0.42(0.41)$ & $<0.0001^{k}$ \\
\hline Proteinuria (gr/day) & $566(4997)$ & $1057(4630)$ & 709.5 (2808) & $93(159)$ & $<0.0001^{k}$ \\
\hline $\mathrm{LDH}(\mathrm{U} / \mathrm{L})$ & $214(508)$ & $273.5(507)$ & $255(364)$ & $144(150)$ & $<0.0001^{k}$ \\
\hline Uric acid (mg/dl) & $4.88 \pm 2.44$ & $6.06 \pm 2.8$ & $4.93 \pm 2.1$ & $3.62 \pm 1.68$ & $<0.0001^{\circ}$ \\
\hline
\end{tabular}




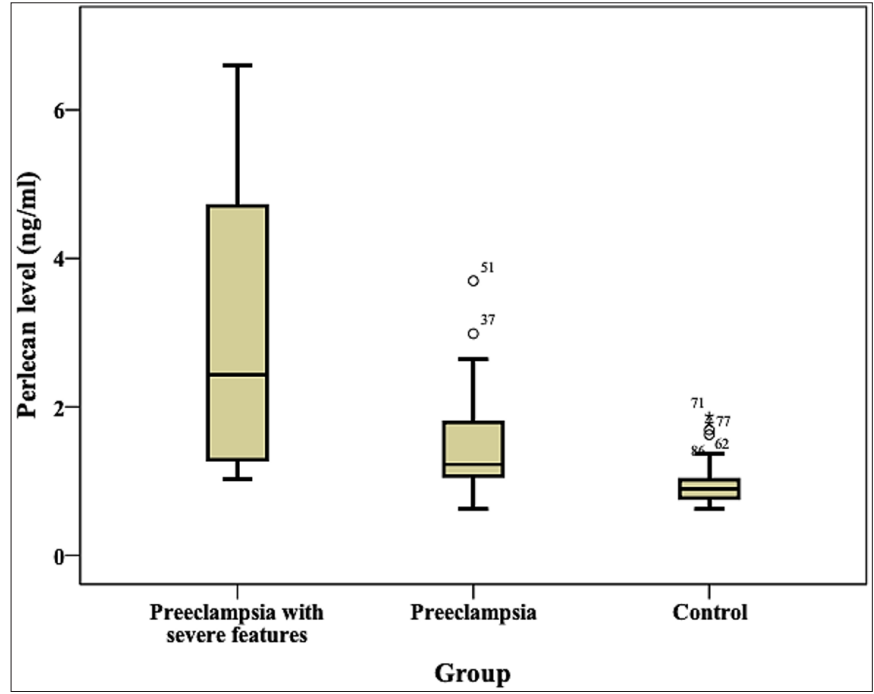

Figure. Distribution of perlecan levels between groups and their mean values

\section{DISCUSSION}

In our study, we found that the perlecan level was higher in the severe and mild preeclampsia group than in the control group. In addition, we found that perlecan level increased in the severe preeclampsia group in proportion to systolic and diastolic blood pressures, liver and kidney function tests.

In the study of Akbaş et al. (14) another study similar to our study, perlecan level was found to be high in severe preeclampsia cases. This study is important as it is a preliminary study that suggests that perlecan may play a role in the pathogenesis of preeclampsia. However, that study differs from our study in that the perlecan level was found to be high only in severe preeclampsia cases and a significant increase was not found in mild preeclampsia cases. In this study, we considered that perlecan level may be different in cases of preeclampsia and this may be due to the effects of proteoglycans on placental development and regulation of autophagy. The high perlecan level in both mild and severe preeclampsia cases we observed in our study supports the idea that perlecan may play a role in the pathogenesis of preeclampsia. In addition, the increased perlecan level in the severe preeclampsia group in proportion to systolic and diastolic blood pressures and liver and kidney function tests suggests that there may be a relationship between preeclampsia severity and perlecan level. It is possible to consider that as the severity of preeclampsia increases, the severity of autophagy, which is shown to be responsible for the pathogenesis process, also increases and the level of perlecan increases as a defense mechanism that prevents it.

Although Szenasi et al. (15) found increased perlecan levels in early preeclampsia in a similar study, they did not detect an increase in perlecan levels in late preeclampsia. In this study, it was concluded that the pathology of early preeclampsia was caused by abnormal trophoblast invasion-ischemic damage-placental stress, whereas late preeclampsia was based on a different pathology. In this study, it was found that the perlecan level decreased as the gestation period progressed. Yang et al. (16) found that perlecan level decreased as gestational age progressed, and perlecan level increased as gestational age progressed in those with gestational diabetes. In this study, hyperglycemia increased the level of perlecan. Confirming the information obtained from these studies, the high level of perlecan in preeclampsia suggests that perlecan is secreted as a defense molecule against abnormal processes in the body. It is a protective molecule and its level increases as a response to the abnormal autophagic reaction known to play a role in the pathogenesis of preeclampsia.

In another study for preeclampsia cases, it has been found that mRNA and protein expression of perlecan was significantly reduced. Perlecan has an angiogenesisinducing effect and a decrease in perlecan level contributes to the pathogenesis of preeclampsia by reducing trophoblast invasion (17). Another study conducted to determine biological markers in cases with premature rupture of membranes found that perlecan level did not decrease in amniotic fluid, and although the role of heparan sulfate-derived proteoglycans in amniotic fluid is not known precisely, it has been considered to have a growth factor-like effect (13).

In a study by Zhao et al. (18) they showed that inhibition of protein kinase $\mathrm{C}$ beta increases autophagic activity and this increase triggers preeclampsia in both humans and animals. Recent studies report that the same inhibition triggers autophagy in preeclampsia after it has been shown that histone deacetylase inhibition triggers autophagy in multiple myeloma (19). Other studies report that autophagy activation is also associated with the enhancement of immune response and this affects the pathogenesis of preeclampsia (20). Similarly, we found the increased level of perlecan, although no evidence had about autophagy in our study. When the literature is reviewed, despite the findings of previous studies that inhibition of autophagy triggers preeclampsia, recent studies suggest that the increase in autophagy is more effective in the pathogenesis of preeclampsia (4).

A small number of patients and the lack of shorter gestational weeks are the limiting factors of our study. Besides, we should mention absence of placental level evaluation, absence of the parturition data, absence of umblical cord blood level and absence of the relation between perlecan level and neonate birthweight and APGAR score in the present study. 


\section{CONCLUSION}

The maternal serum perlecan level was higher in the severe and mild preeclampsia group than in the control. In addition, perlecan level increased in the severe preeclampsia group in proportion to systolic and diastolic blood pressures, liver and kidney function tests. Based on the findings we obtained from our study consider that perlecan may be biochemical for understanding preeclampsia cases. Findings of the present study will be a guide for further studies to explain the relationship between perlecan and preeclampsia.

\section{ETHICAL DECLARATIONS}

Ethics Committee Approval: Approval was obtained from Clinical Research Ethics Committee of Kahramanmaraş Sütçü İmam University, Faculty of Medicine (Date: 29/08/2018, Decision No: 06, Session: 2018/5).

Informed Consent: All patients signed the free and informed consent form.

Referee Evaluation Process: Externally peer-reviewed.

Conflict of Interest Statement: The authors have no conflicts of interest to declare.

Financial Disclosure: The authors declared that this study has received no financial support.

Author Contributions: All of the authors declare that they have all participated in the design, execution, and analysis of the paper, and that they have approved the final version.

\section{REFERENCES}

1. El-Sayed AAF. Preeclampsia: A review of the pathogenesis and possible management strategies based on its pathophysiological derangements. Taiwanese J Obstet Gynecol 2017; 56: 593-8.

2. Abalos E, Cuesta C, Grosso AL, Chou D, Say L. Global and regional estimates of preeclampsia and eclampsia: a systematic review. Eur J Obstet Gynecol Reprod Biol 2013; 170: 1-7.

3. Oh SY, Hwang JR, Choi M, et al. Autophagy regulates trophoblast invasion by targeting NF- $\mathrm{B}$ activity. Scientific Reports Sci Rep.2020; 10: 14033.

4. Nakashima A, Aoki A, Kusabiraki T, Cheng SB, Sharma S, Saito S. Autophagy regulation in preeclampsia: Pros and cons. Journal of Reproductive Immunology 2017; 123: 17-23.

5. Karumanchi SA, Bdolah Y. Hypoxia and sFlt-1 in preeclampsia: the "chickenand-egg" question, Endocrinology 2004; 145: 4835-7.

6. Smets EML, Visser, Go ATJI, Vugt JMGV, Oudejans CBM. Novel biomarkers in preeclampsia. Clin Chim Acta 2006; 364: 22-32.

7. Ramos JGL, Sass N, Costa SHM. Preeclampsia. Rev Bras Ginecol Obstet 2017; 39: 496-512.

8. Nakashima A, Yamanaka-Tatematsu M, Fujita N, et al. Impaired autophagy by soluble endoglin, under physiological hypoxia in early pregnant period, is involved in poor placentation in preeclampsia. Autophagy 2013; 9: 303-16.

9. Kalkat M, Garcia J, Ebrahimi J, et al. Placental autophagy regulation by the BOK-MCL1 rheostat. Autophagy 2013; 9: 214053
10.Jiang X, Couchman JR. Perlecan and tumor angiogenesis. J Histochem Cytochem 2003; 51: 1393-410.

11.Ning L, Xu Z, Furuya N, Nonaka R, Yamada Y, Arikawa-Hirasawa E. Perlecan inhibits autophagy to maintain muscle homeostasis in mouse soleus muscle, Matrix Biol 2015; 48: 26-35.

12. Gubbiotti MA, Neill T, Iozzo RV. A current view of perlecan in physiology and pathology: A mosaic of functions. Matrix Biol 2017; 57-58: 285-98.

13. Vuadens F, Benay C, Crettaz D, et al. Identification of biologic markers of the prematüre rupture of fetal membranes: Proteomic approach. Proteomics 2003; 3: 1521-5.

14. Akbas M, Koyuncu FM, Ulkumen BA, Taneli F, Ozdemir H. Maternal serum perlecan levels in women with preeclampsia. Hypertens Pregnancy 2020; 39: 70-6.

15. Szenasi NL, Toth E, Balogh A, et al. Proteomic identification of membrane-associated placental protein 4 (MP4) as perlecan and characterization of its placental expression in normal and pathologic pregnancies. PeerJ 2019; 7: e6982.

16. Yang WC, Su TH, Yang YC, Chang SC, Chen CY, Chen CP. Altered perlecan expression in placental development and gestational diabetes mellitus. Placenta 2005; 26: 780-8.

17. Chui A, Murthi P, Brennecke SP, Ignjatovic V, Monagle PT, Said JM. The expression of placental proteoglycans in pre-eclampsia. Gynecol Obstet Invest 2012; 73: 277-84.

18. Zhao H, Gong L, Wu S, et al. The inhibition of protein kinase C $\beta$ contributes to the pathogenesis of peeclampsia by activating autophagy. EBioMedicine 2020; 56: 102813.

19. Du J, Ji Q, Dong L, Meng Y, Xin G. HDAC4 Knockdown Induces Preeclampsia Cell Autophagy and Apoptosis by miR-29b. Reprod Sci 2021; 28: 334-42.

20.Cornelius DC, Wallace K. Autophagy in preeclampsia: A new target? EBioMedicine 2020; 57: 102864.

21.Wu PH, Lin YT, Chiu YW, et al. The relationship of indoxyl sulfate and p-cresyl sulfate with target cardiovascular proteins in hemodialysis patients. Sci Rep 2021; 11: 3786.

22. Melrose J. Perlecan, a modular instructive proteoglycan with diverse functional properties. Int J Biochem Cell Biol 2020; 128: 105849.

23.Jansson M, Billing O, Herdenberg $\mathrm{C}$, et al. Expression and circulating levels of perlecan in breast cancer-implications for oestrogen dependent stromal remodeling. J Mammary Gland Biol Neoplasia 2020; 25: 69-77.

24.Mishra M, Chandavarkar V, Naik VV, Kale AD. An immunohistochemical study of basement membrane heparan sulfate proteoglycan (perlecan) in oral epithelial dysplasia and squamous cell carcinoma. JOMFP, 2013; 17: 31-5.

25.Elgundi Z, Papanicolaou M, Major G, et al. Cancer metastasis: the role of the extracellular matrix and the heparan sulfate proteoglycan perlecan. Front Oncol 2020; 9: 1482. 